\title{
Culture's Influence on Cockpit Communication
}

\author{
Shouxi Zhu \\ Flying College \\ Binzhou University \\ Binzhou, China \\ zhushouxi@163.com
}

\author{
Wenlai Ma \\ Flying College \\ Binzhou University \\ Binzhou, China \\ mawenlai@163.com
}

\begin{abstract}
Culture is one of the important factors that affect communication and cockpit resource management (CRM). The paper presents two main theories of cultural studies, respectively is Edward T Hall's high-context culture and low-context culture and Hofstede's cultural dimensions, and then analyzes the culture's influence factors of communication from the two theories. This paper studies the characteristics of Chinese culture and compares the cultural differences between east and west, and then analyzes the main communication characteristics of Chinese pilots in the cockpit from the following four aspects: harmony, relationship, face and power. Finally, from the perspective of culture, the corresponding suggestions to reduce the effects of culture on communication of the cockpit are given. Related research is of great significance to improve flight safety.
\end{abstract}

Keywords- culture; cultural dimensions; crew; flight safety; communication

\section{INTRODUCTION}

Culture refers to common values, traditions, social and political relations and worldview that a group of people creates and shares together. It is a comprehensive by some factors, including a common history, geographical environment, language, social status and beliefs. Culture is maintained by communication, at the same time, presents through communication. Culture can affect everything in our life, it will affect a person's natural way of thinking, value orientation, cognitive process and communication mode quite naturally. For the crew members with strict training, seemingly culture will not directly affect the communication. Nevertheless, in fact, culture wills subtle influence the process of communication, decision-making and even the final implementation [1]. With the development of internationalization of China's civil aviation, more and more foreigners join the pilot team of China, therefore, cross-cultural communication will lead to more problems [2]. According to statistics, more than half of flight accident factors are CRM and cultural factor is one of the important factors that affect the communication and the CRM, so it is necessary to discuss the cultural problems in flight.

\section{Two MAIN TheORIES OF CUltural Studies}

\section{A. Hall' Theory}

From the perspective of communication, the famous American anthropologist Edward T. Hall proposed high- context and low-context culture [3]. According to the accuracy and clarity of information transmission and receiving in communication, culture can be divided into high-context and low-context culture. In Hall' theory, "context" is the information that surrounds an event, and the "event" is the contents to be expressed. Their combination can reflect the characteristics of a culture.

High-context culture is more obvious in the eastern culture, such as China, Japan and South Korea, which also exists in family-run enterprises in the early industrialization of western. More generally, it can be understood as a culture with heavy emotional and interpersonal. The messages are simple or ambiguous in high-context culture and the expression is indirect. Its main characteristics are:

- Disconsider the dominant oral information.

- The important information is usually reflected in time, space, situation, relationship and other situational clues.

- Highly emphasis on harmony, and tend to use vague language and prefer silence.

- Not directly touch the key when speaking and avoid direct say "No".

Low-context culture is more obvious in most European and American countries, such as the United States, Canada, Germany, etc. This culture emphasizes direct communication to exchange information and do not attach importance to interpersonal relationships. Generally it has individualism tendency and using the linear logical way. The main features in the aspect of communication are:

- Disconsider the situational context in the process of communication.

- Important information usually through explicit oral expression.

- Attaches great importance to the presentations and fluent language expression, like speech.

- Direct statement to his own opinion, and tries to persuade the other to accept his point of view.

According to Hall' theory, compared to the United States and other western countries, the communication of the Chinese pilot is more tactful and avoids saying no. Therefore, when confronted with an emergency situation he may delay time. Direct expression of western pilot is good for flight safety, but he may cause dissatisfaction with the pilots in China. 


\section{B. Hofstede's Cultural Dimensions Theory}

Hofstede developed the cultural dimensions theory which is used widely as a crucial framework for crosscultural communication. It could be quantified and used to explain perceived differences between cultures. Hofstede's theory identified six dimensions of culture, which are power distance, individualism vs collectivism, uncertainty avoidance, masculinity vs femininity, short-term vs longterm orientation, and indulgence vs self-restraint [4]. The first four dimensions have a larger impact on the cockpit communication.

1) Power distance: Power distance is the degree of equality between people of different countries, as well as the acceptance of members of society to unequal distribution of power. High power distance means that members of society have a high degree of recognition to social differences caused by the sectors of power and wealth. These societies generally tend to follow social hierarchy system. Low power distance culture considered that the members of an organization should respect each other as equals. Pilots from high power distance countries (China and Southeast Asian countries, etc.), the copilot rarely questioned the captain's decision-making and operational behavior, even though the captain's decisions are not appropriate. They pay attention to the wording in communication, the more hesitant to express their views, to worry about offending the captain and punished, tend to accept autocratic leadership style, one-way communication is more. Pilots from low power distance countries (United States, Canada, Australia, etc.), the pilots are more equal when communication in the cockpit. When questioned, the copilot tended to bold, direct and two-way communication. The use of automation equipment, including the usage preferences and opinions, etc., will also be influenced by culture. Pilots from high power distance cultures support a more positive attitude to the use of automation equipment, and tend to use in various situations [5].

2) Individualism vs collectivism: Individualism vs collectivism reflects the recognition degree of society for different personal achievement and different relationships of community members. Individualism cultures emphasize self-awareness, pay attention to personal goals and independent, respect competition; and collectivism culture is "our" culture, consider that individual should be associated with the group members. This culture attaches great importance to the members loyalty as well as harmony between members. United States and Australia, etc., more emphasize on individualism, while many Latin American and Asian countries, more emphasize on collectivism. Pilots from individualism culture countries tend to change their action style in order to maintain interpersonal harmony, and showing a tendency of teamwork. However, this culture prone avoids the phenomenon of disagreement or conflict during flight.

3) Uncertainty avoidance: Uncertainty avoidance reflects to society's tolerance for uncertainty and vague concepts. In high uncertainty avoidance society, people feel anxiety and unease for uncertain or ambiguous factors. To increase the increase the predictability of things development, people will develop a variety of rules and regulations. In low uncertainty avoidance society, people can embrace the uncertainties and show a greater tolerance on the vague concept and heresy. The United States, Europe and other countries belong to the low uncertainty avoidance cultures, while China and Southeast Asia countries belong to the high uncertainty avoidance cultures. High uncertainty avoidance cultures tend to follow standard operating procedures (SOP), consider that the standard operating procedures are applicable in any situation. However, low uncertainty avoidance cultures will perform better in an abnormal situation than high uncertainty avoidance cultures [6].

4) Masculinity vs femininity: In masculinity society, men have greater authority and control power, the dominant values emphasize competition, achievement and success. In femininity society, men and women is more equal, the dominant values emphasize the solidarity among members, harmony and mutual caring. Compared to the masculinity society, such as the United States, Canada and other countries, the culture of China and Southeast Asian countries reflect more feminine, attention to interpersonal harmony and maintain relationships, attention to maintain each other's face or self-esteem. Therefore, the actions such as inquiry, remind or correct in cockpit are relatively few.

\section{CHARACTERISTICS OF CHINESE CULTURE AND ITS INFLUENCE ON COCKPIT COMMUNICATION}

Eastern culture represented by China comes mainly from the culture of the Yellow River Valley and the culture of the Indus valley. The characteristics of the eastern culture are the conception of "harmony between human and nature", very mysterious and attach importance to emotion. Western culture mainly comes from the Greek culture and Christian culture, the characteristics of western culture are respect for human, the pursuit of individual freedom, independence, equality and emphasis on the performance of the personality. Different sources of eastern and western cultures cause the different cultural characteristics, as shown in TABLE I. 
TABLE I. Cultural Differences Between East AND West

\begin{tabular}{|c|c|c|}
\hline Compared Aspects & East & West \\
\hline Cultural type & Agricultural culture & Commercial culture \\
\hline Cultural traits & Spiritual culture & Material culture \\
\hline Cultural values & Heaven-man unity & Man can conquer nature \\
\hline National mythology & Lymphatic and melancholic & Sanguine and choleric \\
\hline Thinking modes & Integral thinking & Distributed thinking \\
\hline Linguistic symbol & Noninflectional language & Inflectional language \\
\hline Cognitive style & Experience rationality & Logic rationality \\
\hline Behavior style & Keep off the spot & Seeking change \\
\hline Science/technology & Knowledge and experience & Theory and practice \\
\hline Educational mode & Enclosed force-feeding education & Open heuristic education \\
\hline Time orientation & Emphasize past and ancestor-worship & Emphasize present \\
\hline Interpersonal relationship & Collectivism & Individualism \\
\hline Time concept & Multiple linear time & Single linear time \\
\hline
\end{tabular}

From the table, we can see that aspects involved of culture are various. From the description above mentioned, we can understand the Chinese culture effect on the cockpit communication to a certain extent. Chinese culture has many characteristics. In general, the main factors influencing the Chinese communication can be summarized as: harmony, relationship, face and power [7].

\section{A. Harmony}

Harmony is the main value orientation of the Chinese culture. Because the view of harmony, Chinese pilots tend to avoid direct put forward their own opinions and suggestions. In order to avoid the conflict, they also have difficult to insist on their opinions. The cockpit with view of harmony will lead to the cooperate looks good, but in fact, a lot of problems in flight and unsafe factors can be selectively ignore, which may reduce the flight standards to a certain extent.

\section{B. Relationship}

Relationship is the established mutual dependence network between two people or two groups. Relationship is very important in Chinese culture and can distinguish we-group and others-group. The special relationship that belongs to "we-group" often can resolve the conflict effectively and promote the unity of opinion. The influence of relationship on crew communication is two sides: on the one hand, a good relationship can promote the solution of problems, keep a good atmosphere and lead to a good communication and collaboration; On the other hand, if too emphasize on relationship, may also cause lower standard and increase hidden trouble of flight safety.

\section{Face}

Face can be defined as the projected image in interpersonal relationships. Face represents the image of a person and represents one's authority and position in a group. The Chinese attach great importance to face, if a person has made others loss face, not only others lose face, his image will also be disparaged. So in this culture, crew members are often reluctant to point out other people's problems, thus reduce the whole crew's decision-making ability. Furthermore, if there is a problem, under the condition of taking account of face, he may blindly or concealed and unreported which will lead to an accident. Confidential aviation safety reporting systems are an effective way to solve this problem. The anonymous reporting system without punishment can not only consider the face but also find problems and hidden dangers timely.

\section{Power}

Chinese culture is with high power distance. There is a fear of power phenomenon in the whole society [8]. In a sense, power represents the capacity, position and seniority. In the crew members, no matter the power obtained by an organization authorized, age long or long flight qualifications, as long as he is the person who has the authority, such as the captain, his voice will make up a large proportion. Fear of power of Chinese pilots will lead to their trust blindly captain's suggestions and opinions, not willing to, don't know, or dare not to present contrary opinions. Thus, the authority and assertiveness will unbalance, the flight becomes one thing of one person, the monitoring role between crew members will be weakened.

\section{CORRESPONDING MEASURES}

\section{A. Reasonable CRM training}

Culture will affect the training effect of CRM, thus during CRM training, we should consider the national cultural differences and adjust it [9]. CRM training courses In American, for example, to avoid individualism tendency, we should emphasize teamwork, conflict resolution and leadership; because China belongs to the collectivist culture with high power distance, therefore the CRM training should weaken the authority of captain, emphasize 
two-way communication, attaches great importance to decision-making, inquiry and persistence, etc. In addition, cooperation between different organizational culture and its impact on CRM should also be involved in the CRM training.

\section{B. Adhere to Standard Operating Procedures}

The negative impact of China authority culture on crew behavior cannot be completely eliminated by CRM training. For this reason, considering the China culture has the characteristic of high uncertainty avoidance and pilots tend to follow the rules and SOP, and insist on the program, we can consider incorporating the concept of crew collaboration into operation manual, procedures and SOP to regulate and fix the crew behavior. Such as regulating the inquiry and advice language, stipulating the standard language when in danger, etc. [10].

\section{Emphasis on the Construction of Organizational Culture}

Operation based on regulations and programs is the foundation of the flight safety. Airlines should create a supportive organizational culture, emphasizes the high coordination and cooperation, encourage crew members (especially co-pilot) dare to express or stick to their ideas in the cockpit to produce more cooperation behaviors that help to security. Reduce the otherness between the crew internal rules and written rules, ensure the whole company really produces the thought of "safety first".

\section{CONCLUSIONS}

Culture has both positive and negative influences on the cockpit communication. Harmony and obedience to authority are two important characteristics of Chinese culture. Those cultural characteristics will cause more prominent negative effect on the crew members' interaction, communication and decision-making. We can through strengthen the CRM training, improve the operation manual, procedures and so on, so as to enhance the collaboration concept of crew, and then to reduce the bad culture's influence on the cockpit communication as far as possible.

\section{ACKNOWLEDGMENT}

This research was financially supported by scientific research project of Binzhou University (Grant NO.BZXYG1316, BZXYG1320).

\section{REFERENCES}

[1] SX. Zhu and WL. Ma, "Cockpit/cabin Crew Communication: Problems and Countermeasures," Advances in Social Science Education and Humanities Research, vol. 17, pp. 508-512, January, 2015.

[2] K. Tylén and J. J. Mcgraw, "Materializing Mind: The Role of Objects in Cognition and Culture," in Perspectives on Social Ontology and Social Cognition, vol. 4, Springer Netherlands, 2014, pp. 135-148.

[3] Edward T. Hall, The Silent Language. Beijing: Peking University Press, 2010

[4] G. Hofstede, Cultures and organizations: Software of the mind. Maidenhead, UK: McGraw-Hill, 1991.

[5] A. Merritt, "Culture in the cockpit: do Hofstede's dimensions replicate," Journal of Cross-cultural Psychology, vol. 31, pp. 283301, March, 2000.

[6] G. Grote, M. Kolbe, E. Zala-Mezö, N. Bienefeld and B. Künzle, "Adaptive coordination and heedfulness make better cockpit crews," Ergonomics, vol. 53, pp. 211-228, February, 2010.

[7] J. G. Guns and A. A. Harrison, "Cross-Cultural and Spaceflight Psychology: Arenas for Synergistic Research," in on Orbit and Beyond, Springer Berlin Heidelberg, 2013, pp. 211-228.

[8] M. A. Alam, "Cockpit learning in power distant cockpits: The interaction effect of pilot's interdependence and inclination to teamwork in airline industry," Journal of Air Transport Management, vol. 42, pp. 192-202, January, 2015.

[9] M. K. Hughes, R. S. Benenson and A. E. Krichten, "A Crew Resource Management Program Tailored to Trauma Resuscitation Improves Team Behavior and Communication," Journal of the American College of Surgeons, vol. 219, pp.545-551, March, 2014.

[10] J. Ford, R. Henderson and D. O'Hare, "Barriers to Intra-Aircraft Communication and Safety: The Perspective of the Flight Attendants," International Journal of Aviation Psychology, vol. 23, pp. 368-387, October, 2015. 